\title{
ANÁLISE DO PERFIL DO INVESTIDOR DE UM AGENTE AUTÔNOMO DE INVESTIMENTOS
}

\author{
Bruno Pozza Gutller (Universidade do Estado de Santa Catarina - UDESC) guttler.bruno@gmail.com \\ Valdesio Benevenutti (Universidade do Estado de Santa Catarina - UDESC) valdesio.benevenutti@udesc.br
}

\begin{abstract}
Resumo
O presente estudo tem como objetivo a análise do perfil de investidores de um agente autônomo de investimentos para uma melhor alocação estratégica dos recursos. Para tal, foi realizada uma pesquisa bibliográfica sobre o tema e na sequência desenvolvida e aplicada uma pesquisa quantitativa com 102 clientes. O estudo possibilitou também verificar a aplicação de teorias comportamentais nas decisões de investimentos, em especial a Prospect Theory de Kahneman e Tversky. Os resultados obtidos nesta análise sugerem indícios fortes do viés de aversão à perda. Também foi observado que existem conceitos em relação a risco, prazo e retorno que precisam ser melhor esclarecidos para aprimorar os portfólios de investimentos frente a nova realidade de redução significativa das taxas de juros estruturais do mundo e país, e ainda assim mantendo uma duradoura alocação estratégica de investimentos.
\end{abstract}

Palavras-chave: Alocação Estratégica, Mercado Financeiro, Perfil de Investimento. 


\section{Introdução}

Com a taxa básica de juros (SELIC) nos menores patamares históricos, o Brasil entra em uma nova fase econômica nunca antes experimentada. Sempre fomos um país conhecido por juros altos, enquanto as principais economias do mundo reduziram suas taxas básicas ano após ano. Em um cenário de juros elevados é mais fácil para o poupador rentabilizar melhor seu patrimônio, porém o chamado "rentismo" está cada vez menor e o Brasil caminha para taxas similares aos países desenvolvidos. Nessas condições, para continuar obtendo retornos expressivos em seus investimentos o brasileiro precisará investir com mais risco, prazos maiores ou, idealmente, ambos os fatores.

Observando o histórico do mercado de capitais nos últimos anos, principalmente após a implantação do Plano Real, percebe-se uma vasta e crescente possibilidade de investimentos Esse novo contexto foi possibilitado pela estabilização da economia e incremento no volume monetário das transações.

A oferta de produtos e serviços vem se tornando cada dia maior e mais competitiva tendo como consequência direta, o aumento no número de investidores do mercado financeiro. De acordo com o Instituto Assaf (2012) entre dezembro de 2009 e setembro de 2014 o volume de aplicações financeiras cresceu $61 \%$ atingindo o montante de $\mathrm{R} \$ 3,5$ trilhões de reais, entre as modalidades de Poupança, Fundos de Investimentos e Depósitos a Prazo.

No cenário externo já se encara uma nova realidade e perspectiva, a dos juros negativos. Olhando para o Brasil, estamos longe dessa prática, mas é inegável que nossos juros também caminham para níveis cada vez menores, e nesse contexto uma alternativa que cada vez mais se populariza no auxílio de investidores para montagem de carteiras de investimentos visando remunerar melhor o capital próprio são os agentes autônomos de investimentos, que atuam de forma educacional para a distribuição independente de produtos financeiros. 
Esse movimento ainda está em processo de maturação se comparado a países desenvolvidos como: Estados Unidos, Inglaterra e Canadá. Os escritórios, denominados também Agentes Autônomos de Investimentos (Pessoa Jurídica) reúnem diversos investidores pessoa física ou jurídica, com seus objetivos e necessidades próprias.

Em todos os casos, a vantagem é que o investidor que usualmente não consegue estudar e se organizar individualmente para sua organização financeira pode vir a investir de diferentes modalidades de investimento sem precisar ter muito conhecimento prévio do mercado, através dos agentes intermediadores (assessores de investimentos).

Nesse cenário, surge em 2009 o agente autônomo de investimento no interior do Estado de Santa Catarina. Em sua trajetória de 10 anos de existência, presenciou diferentes situações econômicas, acumulando vasta experiência de mercado.

Somando-se as diversas possibilidades de investimentos com a nova conjuntura econômica, algumas dificuldades começam a se apresentar durante o processo decisório para a montagem de um portfólio de investimentos. Mesmo com todo o conhecimento técnico, os profissionais da empresa ainda possuem dificuldade para identificar o perfil do investidor logo no início das interações e aplicações iniciais. Uma consequência comum e possível é a frustração de expectativas seguidas de resgates antecipados, além de uma maior necessidade de realocação dentro de um portfólio. Enquadra-se assim o escritório em uma alocação tática de investimentos, com demasiadas movimentações e trocas de investimentos e aumento de risco para o investidor. Essa forma de alocação demanda tempo excessivo dos assessores tanto no acompanhamento quanto na identificação de novas oportunidades e negociação das mesmas com os clientes. Não bastando, em muitos casos o resultado dessas movimentações são retornos menores para intervalos de tempos maiores. Pergunta-se então, como melhor alocar os diversos perfis nesse novo cenário?

Nesse contexto, o objetivo geral deste estudo foi analisar o perfil dos atuais investidores para melhorar a alocação futura de investimentos, migrando os portfólios de atuais e futuros 
clientes para uma alocação estratégica de recursos, com ampliação dos prazos de aplicação e por consequência maiores retornos, além de indiretamente trazer mais produtividade para o agente autônomo de investimnetos.

Para que isso seja possível, foi necessário entender com maior profundidade o perfil, prazos, objetivos e comportamentos dos atuais investidores. O desdobramento do objetivo geral se dá através dos seguintes objetivos específicos:

a) Apresentar os princípios e conceitos mais relevantes das finanças comportamentais;

b) Identificar tendências comportamentais dos investidores em cenários de ganhos e perdas;

c) Identificar tendências relacionadas a fatores sociodemográficos.

\section{Fundamentação teórica}

\subsection{Alocação de recursos}

Segundo Pinheiro (2001), as características principais dos ativos financeiros dividem-se em três: Liquidez, Risco e Rentabilidade.

Em geral, a rentabilidade é uma função que depende da liquidez e do risco, ou seja:

$$
R=F(L, r)
$$

Onde: $R=$ rentabilidade, $L=$ liquidez, $r=$ risco

Mishkin (2000, p. 4), classifica os três fatores:

Ao tomar a decisão sobre a compra ou a posse de um ativo, ou comprar um ativo em vez de outro, um indivíduo deve considerar os seguintes fatores: sua riqueza (somatório de todos os bens e ativos); a rentabilidade esperada (retorno esperado de um ativo em relação aos ativos alternativos); o risco (grau de incerteza associado ao retorno) e a liquidez (a facilidade e rapidez com as quais um ativo pode se transformar em dinheiro)." 
As diferentes modalidades de ativos financeiros geram-se por combinações específicas dessas três características descritas.

\subsection{Vieses comportamentais}

A análise dos vieses que afetam as decisões dos investidores é fundamental. Segundo Kahneman e Tversky (1979), os vieses cognitivos, são "atalhos mentais", pois podem levar os investidores ao erro sem mesmo que eles percebam. Logo a compreensão dos mesmos é essencial para obter uma melhor visão sobre como os investidores criam e administram suas expectativas quanto a retornos.

a) Aversão a Perdas

Este viés trata da diferença de valor subjetivo entre ganhos e perdas - sendo a perda sentida com muito mais intensidade do que o ganho e contrariando conceitos econômicos fundamentalistas. Estudos famosos têm mostrado que as pessoas tendem a ser avessas ao risco quando se trata de ganhos e são propensas a correr riscos a fim de evitar ou compensar perdas (SILVA e ARAÚJO, 2008).

b) Ancoragem: Consiste na atribuição de demasiada importância a uma determinada informação, a chamada âncora, quando se toma decisões (LOBÃO, 2012). Kahneman e Tversky (1979) defendem que muitos ficam "presos" a cenários que lhes sejam familiares e somente ajustem pequenas informações conforme as novas informações, fazendo muitas vezes com que os investidores fiquem sugestionados com os preçosalvos divulgados pelos analistas.

c) Excesso de confiança: Segundo Thaler e Barberis (2003), o excesso de confiança pode em parte, resultar de outros dois preconceitos, como o viés da auto atribuição (tendência de atribuir qualquer sucesso aos seus próprios talentos) ou o viés do retrospecto (tendência das pessoas acreditarem, depois de um evento ter acontecido, que o previram antes que acontecesse). 


\subsection{Teoria do Prospecto}

Nesse campo surge a Prospect Theory (teoria do prospecto ou perspectiva) em 1979 por Daniel Kahneman e Amos Tversky afirmando que as pessoas tomam decisões mais baseadas em potenciais valores de perdas e ganhos do que no resultado final, contrariando o paradigma até então vigente estabelecido pela Economia Neoclássica e pelas Finanças Tradicionais.

Lobão (2012) complementa a teoria ponderando que as pessoas encaram eventos extremamente improváveis como impossíveis e eventos extremamente prováveis como certos. Também evidencia essa demonstração contrária de valor psicológico, mostrando como um ponto de referência pode influenciar as tomadas de decisão dos indivíduos. Quando chamados a fazer uma escolha entre as seguintes situações,

$1^{\mathrm{a}}$ escolha - Em posse em $€ 20.000$ escolher uma das seguintes alternativas de jogo:

a1: Receber $€ 5.000$ com uma probabilidade de $100 \%$;

b1: Receber $€ 10.000$ com uma probabilidade de $50 \%$.

$2^{\text {a }}$ escolha - Agora em posse de $€ 30.000$, escolher uma das seguintes alternativas de jogo:

a2: Perder $€ 5.000$ com uma probabilidade de $100 \%$

b2: Perder $€ 10.000$ com uma probabilidade de $50 \%$ 
Teoricamente em uma análise racional a abordagem e decisão tomada seriam as mesmas para ambos os cenários visto que as escolhas a1 e a2 resultam em uma posição final de €25.000. Sendo assim seria racional fazer a escolha de a1 e a2 ou b1 e b2. Entretanto, a maioria dos indivíduos encara como escolhas diferentes, tendendo a escolher a opção a1 de menos risco para um cenário positivo, de ganhos, e b2, com mais risco para um cenário negativo, de perdas, indicando aversão ao risco quando ganhando e também aversão ao risco quando perdendo.

A explicação apresentada por essa mesma Teoria da Perspectiva defende que há uma resistência dos indivíduos em aceitarem perdas, dessa forma fazendo com que tomem mais risco, se no seu entendimento isso evitar a possibilidade das mesmas. Porém quando falando de ganhos esse comportamento não é o mesmo, sendo mais comum os indivíduos aceitarem menos risco em hipóteses de igual valor desde que a possibilidade de ganho seja maior. Complementar a essa questão, Kahneman e Tversky (1979) propuseram um segundo jogo:

a) $50 \%$ de probabilidade de perder $€ 100$

b) $50 \%$ de probabilidade de ganhar $€ 150$

Novamente contrariando os modelos racionais, evidências demonstram que a maioria dos indivíduos tende a descartar o jogo em que tenham iguais possibilidades de ganho e perda, excetuando-se a situação onde o ganho potencial for duas vezes superior à perda potencial, como:

a) $50 \%$ de probabilidade de perder $€ 100$

b) $50 \%$ de probabilidade de ganhar $€ 200$

Como pontuam Silva e Araújo (2008), os investidores sentem muito mais a dor da perda do que o prazer obtido com um ganho equivalente. 


\subsection{Perfil do investidor}

Para analisar um investimento é preciso classificá-lo quanto aos conceitos de risco e retorno, para dessa forma comparar entre outros ativos e ser possível uma melhor tomada de decisão de acordo com os objetivos e capacidades do investidor.

\subsubsection{Risco e Retorno}

Conforme definiu Assaf Neto (2011): "O risco pode ser entendido pela capacidade de mensurar o estado de incerteza de uma decisão mediante um conhecimento das probabilidades associadas à ocorrência de determinados resultados ou valores."

\section{a) Aversão ao Risco}

Segundo Simon (1996), quem apresenta aversão ao risco tem uma chance muito grande de fazer parte de um estilo conservador, sem tolerância ao mesmo. Esse perfil é o mais comum, formado por investidores que ponderam mais a segurança do que os ganhos para seus ativos. Uma pessoa que prefere uma renda garantida a uma renda de risco com o mesmo valor esperado é considerada avessa a riscos.

b) Neutralidade ao Risco

A Neutralidade aponta um perfil moderado quanto à tomada de decisões. Segundo Pindyck e Rubinfeld (2002), quando existe essa característica o indivíduo é indiferente ao recebimento de uma renda certa e o recebimento de uma renda incerta que apresente o mesmo valor da renda esperada, ou seja, tende a dar importância a perdas e ganhos na mesma proporção, apresentando estabilidade, e caracterizando um comportamento moderado em relação ao risco.

c) Apreciação ao Risco

Como disseram Haiffa et al (1995), um investidor que aprecia o risco está em busca de 
retornos potenciais elevados, mesmo que a probabilidade exista de obter um resultado exatamente oposto como perdas. Como disseram também Pindyck e Rubinfeld (2002), um indivíduo tem apreciação ao risco quando prefere a aposta (renda incerta), à renda garantida.

\section{Metodologia}

A pesquisa foi realizada através das seguintes etapas:

a) Revisão bibliográfica para entender melhor as teorias envolvidas e estudos já realizados relacionados ao tema.

b) Desenvolvimento de questionário com 30 questões fechadas, pré-testados e após coleta das respostas e discussão interna com outros assessores do escritório, enviar aos sujeitos da amostra. As questões foram elaboradas utilizando como referência pesquisas de Kahneman e Tversky, visando validar a teoria do prospecto, além de alguns outros vieses comportamentais de investimento.

c) Delimitação dos pesquisados através da seleção dos investidores com um patrimônio aplicado igual ou superior a $\mathrm{R} \$ 50.000,00$, visto que dessa forma é possível uma maior diversificação de ativos e alocação de uma carteira mais completa de investimentos. Dos 183 clientes com este perfil, 102 responderam o questionário que foi enviado por e-mail e mensagens diretas via aplicativo de celular WhatsApp.

d) Coleta de dados: A pesquisa foi realizada com investidores no mês de setembro de 2019, iniciando dia 10 e finalizando dia 25 do mesmo mês.

e) Tratamento de dados é quantitativa em relação a escolha de dados financeiros, prazos e valores percentuais, além da tomada de decisão dos investidores. Para evidenciar resultados serão utilizadas comparações percentuais em forma de tabelas.

\section{Resultados e discussões}

4.1 Análise da persona 
Nesta seção da pesquisa foram feitos questionamentos para os clientes, com o intuito de identificar inicialmente as características demográficas e algumas definições sobre investimentos.

A maior concentração de idade entre 25 e 44 anos, se somadas, resultando em $61,10 \%$ da amostra, embora não necessariamente equivale a concentração de custódia.

O sexo do investidor é majoritariamente masculino para a amostra $(83,50 \%)$, denotando uma realidade muito comum no cenário de investimentos nacional, onde os homens têm um maior contato com essa tarefa ou em muitos casos, como do escritório estudado, concentram em sua conta os valores da família e são os responsáveis pela organização financeira.

A renda é bem distribuída, mas com maior concentração entre $\mathrm{R} \$ 5.001,00$ - $\mathrm{R} \$ 10.000,00$ $(30,10 \%)$. Como a pesquisa considerou apenas os investidores com um patrimônio maior ou igual $\mathrm{R} \$ 50$ mil reais automaticamente foi limitado o número de investidores com renda de até $\mathrm{R} \$ 5.000,00$.

No quesito profissional, "Empregado" (45,10\%) foi a mais escolhida, refletindo a realidade do país onde a maior parte da população é classificada na categoria. Ao mesmo tempo nota-se uma relevante quantidade de autônomos $(23,53 \%)$ e empregadores $(13,73 \%)$, denotando uma quantidade empreendedora relevante $(37,26 \%$ dos pesquisados quando somados).

Quando o assunto é a estrutura financeira familiar, a opção "sem dependentes financeiros" $(56,90 \%)$ foi a alternativa mais assinalada, o que provavelmente se divide entre pessoas mais jovens ainda sem filhos e pessoas mais velhas com filhos já independentes, e ambos configuram um pré-requisito importante para adição de mais risco em uma carteira de investimentos. O restante dos pesquisados $(43,20 \%)$ possui algum tipo de dependente, o que deve ser considerado em uma sugestão de alocação.

A grande parte da base de investidores já tem experiência com relação a investimentos, geralmente mensuramos longo prazo como acima de 2 anos e nesse contexto temos 55,90\% (mais de 2 anos e mais de 3 anos) dos investidores já tendo investido com esses prazos, o que 
é importante visto que é uma expectativa cada vez mais necessária principalmente em um cenário de juros baixos.

Sobre previdência privada está bem dividida entre clientes com $48 \%$ que possuem e $52 \%$ não possuem, mostrando uma grande oportunidade visto que o escritório faz a distribuição dessa solução financeira, somando-se a circunstância o cenário previdenciário brasileiro, que requer maior cuidado com relação a essa questão.

Quanto a frequência de acompanhamento dos investimentos, a alternativa mais selecionada foi "Todo dia" com 40,20\% das respostas, seguido de "2 vezes por semana" com $24,5 \%$, o que mostra que a grande maioria dos clientes acompanha diretamente suas aplicações.

No primeiro questionamento sobre uma alocação mais arrojada (ações), mesmo que hipotético, a maioria $(66,70 \%)$ opta pelo investimento com menor risco, o que seria um nível mais conservador mesmo dentro de uma classificação arrojada.

Na última pergunta da primeira seção é notório que a prioridade número um dos investidores é Rentabilidade $(77,45 \%)$, porém quando questionados sobre a segunda prioridade há uma divisão entre Segurança $(46,08 \%)$ e Liquidez $(35,29 \%)$.

\subsection{Análise do comportamento de investimento}

Quando perguntados sobre o que a palavra Risco representa, para mais da metade $(55,90 \%)$ é um indicativo de Incerteza conforme mostra a Tabela 1. Um número expressivo também classifica como oportunidade $(34,30 \%)$.

Tabela 1 - Associação com a palavra risco no contexto financeiro.

\begin{tabular}{c|c|c|c}
\hline Pergunta & Opções de Resposta & Quantidade Absoluta & Quantidade Percentual \\
\hline \multirow{3}{*}{$\begin{array}{c}\text { 11. Com o que você associa } \\
\text { a palavra "Risco" em um } \\
\text { contexto financeiro? }\end{array}$} & Perigo & $\mathbf{7}$ & $6,90 \%$ \\
\cline { 2 - 4 } & Incerteza & $\mathbf{5 7}$ & $\mathbf{5 5 , 9 0 \%}$ \\
\cline { 2 - 4 } & Oportunidade & 35 & $34,30 \%$ \\
\hline
\end{tabular}

Fonte: Elaborado pelos autores.

Sobre a seleção de uma carteira de investimentos (Tabela 2), os resultados ficaram bem 
distribuídos com uma concentração maior em uma rentabilidade alvo de $10 \%$ ou perdas de $2 \%$, enquadrando os pesquisados em um caráter mais protecionista.

Tabela 2 - Escolha da carteira de investimentos.

\begin{tabular}{|c|c|c|c|}
\hline Pergunta & Opções de Resposta & Quantidade Absoluta & Quantidade Percentual \\
\hline \multirow{5}{*}{$\begin{array}{l}\text { 12. Você precisa investir } \\
\text { TODO seu dinheiro em uma } \\
\text { única carteira, qual você } \\
\text { escolhe? Valores ao ano: }\end{array}$} & $\begin{array}{c}\text { Carteira A - Rentabilidade de } 6 \% \\
\text { ou perdas de } 0 \%\end{array}$ & 5 & $4,90 \%$ \\
\hline & \begin{tabular}{|c|} 
Carteira B - Possível \\
Rentabilidade de $10 \%$ ou perdas \\
de $-2 \%$ \\
\end{tabular} & 35 & $34,30 \%$ \\
\hline & $\begin{array}{c}\text { Carteira C - Possível Rentabilidade } \\
\text { de } 14 \% \text { ou perdas de }-6 \%\end{array}$ & 26 & $25,50 \%$ \\
\hline & $\begin{array}{c}\text { Carteira D - Possível Rentabilidade } \\
\text { de } 20 \% \text { ou perdas de }-10 \%\end{array}$ & 20 & $19,60 \%$ \\
\hline & $\begin{array}{c}\text { Carteira E - Possível Rentabilidade } \\
\text { de } 30 \% \text { ou perdas de }-14 \%\end{array}$ & 16 & $15,70 \%$ \\
\hline
\end{tabular}

Fonte: Elaborado pelos autores

A tolerância a risco e sua relação com custo perdido foi pesquisada na questão 13 e apresentada uma situação rara, mas que pode acontecer conforme Tabela 3.

Tabela 3 - Investimento em ativo que possa desvalorizar $20 \%$.

\begin{tabular}{|c|c|c|c|}
\hline Pergunta & Opções de Resposta & Quantidade Absoluta & Quantidade Percentua \\
\hline \multirow{5}{*}{$\begin{array}{l}\text { 13. Quanto você investiria em } \\
\text { um ativo isolado que possa } \\
\text { desvalorizar } 20 \% \text { no mês, } \\
\text { mas com potencial de } \\
\text { rentabilidade maior que } \\
\text { todos os outros ativos da } \\
\text { carteira? }\end{array}$} & $0 \%$ dos meus recursos. & 13 & $12,70 \%$ \\
\hline & Até $10 \%$ dos meus recursos. & 55 & $53,90 \%$ \\
\hline & Até $20 \%$ dos meus recursos. & 30 & $29,40 \%$ \\
\hline & De $20 \%$ a $50 \%$ dos meus recursos. & 3 & $2,90 \%$ \\
\hline & Mais de $50 \%$ dos meus recursos. & 1 & $1 \%$ \\
\hline
\end{tabular}

Fonte: Elaborado pelos autores

Comprovou-se que 53,90\% dos pesquisados aceitam investir até $10 \%$ de sua poupança em ativos que possam representar perdas de $20 \%$ no mês, mas com maior potencial de retorno em longo prazo. A opção $20 \%$ dos recursos também teve grande relevância com $29,40 \%$ dos pesquisados. De todo modo evidencia um desafio futuro do escritório, onde para o investidor rentabilizar $10 \%$ ao ano ou mais (principais respostas da questão anterior), o percentual 
alocado em um ativo com a essa característica oscilante (possibilidade de $-20 \%$ ao mês) terá de ser cada vez maior.

A Tabela 4 traz os resultados sobre o tempo de espera que o investidor estaria disposto a aguardar para o investimento retornar ao valor inicial.

Tabela 4 - Tempo de espera para investimento retornar ao valor inicial.

\begin{tabular}{c|c|c|c}
\hline Pergunta & Opções de Resposta & Quantidade Absoluta & Quantidade Percentual \\
\hline \multirow{3}{*}{$\begin{array}{c}\text { 14. Quanto tempo você } \\
\text { estaria confortável em } \\
\text { esperar até seus }\end{array}$} & Até 3 meses & 5 & $4,90 \%$ \\
\cline { 2 - 4 } $\begin{array}{c}\text { investimentos retornarem ao } \\
\text { valor inicial após uma perda? }\end{array}$ & 3 a 6 meses & 15 & $14,70 \%$ \\
\cline { 2 - 4 } & 6 a 12 meses & 28 & $27,50 \%$ \\
\cline { 2 - 4 } & Acima de 18 meses & $\mathbf{2 9}$ & $24,50 \%$ \\
\hline
\end{tabular}

Fonte: Elaborado pelos autores

A maioria estaria confortável em aguardar mais de 12 meses $(24,50 \%)$ e mais de 18 meses (52,90\% acumulado), o que é uma característica positiva, pois é um aspecto importante e que deve ser levado em conta quando aumenta a rentabilidade alvo da carteira de investimentos.

Nas questões (15 e 16), alternando entre cenários de ganho e cenários de perda, buscou-se validar a Teoria do Prospecto, de Kahneman e Tversky entre os pesquisados (Tabela 5).

Tabela 5 - Escolha entre duas opções de investimento (Ganho)

\begin{tabular}{c|c|c|c}
\hline Pergunta & Opções de Resposta & Quantidade Absoluta & Quantidade Percentual \\
\hline \multirow{2}{*}{ 15. O que você escolhe? } & $\begin{array}{c}\text { Ganhar com certeza } \\
\mathbf{R} \$ \mathbf{3 0 . 0 0 0 , 0 0}\end{array}$ & $\mathbf{5 7}$ & $\mathbf{5 5 , 9 0 \%}$ \\
\cline { 2 - 4 } & $\begin{array}{c}\text { Ter } 75 \% \text { de chance de ganhar } \\
\mathrm{R} \$ 40.000,00 \text { e } 25 \% \text { de chance de } \\
\text { ganhar } 0 .\end{array}$ & 45 & $44,10 \%$ \\
\hline
\end{tabular}

Fonte: Elaborado pelos autores.

Na questão 15 verificou-se a inclinação dos investidores quando colocados em cenários de ganho. Como pode ser evidenciado, na maior parte dos casos os investidores tomam a decisão pelo ganho certo, validando a Teoria de Prospecto que explica que investidores tendem a ser avessos ao risco quando estão ganhando.

Já a questão 16 verificou a escolha dos investidores quando colocados em cenários de perda com duas opções de resposta (Tabela, 6). 
Tabela 6 - Escolha entre duas opções de investimento (Perda)

\begin{tabular}{c|c|c|c}
\hline Pergunta & Opções de Resposta & Quantidade Absoluta & Quantidade Percentual \\
\hline \multirow{2}{*}{ 16. O que você escolhe? } & Perder com certeza $\mathrm{R} \$ 30.000,00$. & 34 & $33,30 \%$ \\
\cline { 2 - 4 } & $\begin{array}{c}\text { Ter } 80 \% \text { de chance de } \\
\text { perderR } \$ 45.000,00 \text { e } 20 \% \text { de } \\
\text { chance de perder } \mathbf{R} \$ 0 .\end{array}$ & 68 & $66,70 \%$ \\
\hline
\end{tabular}

Fonte: Elaborado pelos autores.

Contrariando o cenário de ganho, a maioria dos pesquisados $(66,70 \%)$ optou por ter uma chance de perder mais, mesmo que em uma probabilidade menor, validando novamente a Teoria do Prospecto, demonstrando que investidores tendem a tomar mais riscos em um cenário de desvalorização.

\section{Considerações finais}

Conforme evidenciado nos resultados, os investidores apresentam comportamentos diferentes quando trata-se de ganhos ou perdas, mostrando que o viés de aversão a perda, para a grande maioria dos investidores, está intrínseco em nossa forma de pensar no dinheiro. A aversão ao risco dos pesquisados acaba sendo maior quando o mesmo está ganhando do que quando está perdendo, nesse último, a maior parte tende a assumir riscos.

A análise do perfil dos investidores permitiu ainda verificar uma tendência que está ocorrendo durante os últimos anos no mercado financeiro brasileiro. Os indivíduos estão buscando retornos maiores, porém com baixa disposição a tomarem mais risco e incorporar elementos como maior volatilidade e risco ao seu portfólio.

Além disso, a análise do perfil dos atuais investidores do agente autônomo de investimento proporcionou um novo campo de estudo. O desenvolvimento de um programa de captação de novos investidores, tendo como base os principais pontos em destaque deste trabalho. 


\section{REFERÊNCIAS}

ASSAF NETO, Alexandre. Mercado Financeiro. 9a Edição. São Paulo: Atlas, 2011.

INSTITUTO ASSAF. Aumenta estoques de aplicações financeiras no Brasil. Disponível em < http://www.institutoassaf.com.br/2012/download.aspx.> Acesso em 10 set. 2019.

KAHNEMAN D., \& TVERSKY, A. (1979). Prospect theory: An analysis of decision under risk. Econometrica: Journal of the Econometric Society, 263-291.

LOBÃO, J.F. Finanças Comportamentais: Quando a economia encontra a psicologia. Coimbra: Actual, 2012

MISHKIN, Frederic S. Moeda. Moeda, bancos e mercados financeiros. 5. Ed. São Paulo: LTC, 2000, p. 4)

PINDYCK, R. S.; RUBINFELD, D. L. Microeconomia. São Paulo: Prentice Hall, 2002.

PINHEIRO, Juliano. Mercado de Capitais: Fundamentos e Técnicas. 4ª Edição. São Paulo Atlas, 2001.

HAIFFA, R.; PRATT, J. W.; SCHLAIFER, R. Introduction to Statistical Decision Theory. The MIT Press, 1995.

SILVA, César Augusto Tibúrcio; ARAÚJO, Daniel Rosa de. Aversão à perda nas decisões de risco. Revista de Educação e Pesquisa em Contabilidade, v. 2, nº 04, mar 2008.

SIMON, F. Decision Theory: An Introduction to the Mathematics of Rationality. Manchester Ellis Horwood Limited, 1996.

THALER, R.; BARBERIS, N. A survey of behavioral finance. In: CONSTANTINIDES, G.; HARRIS, M.; STULZ, R. (Ed.). Handbook of the economics of finance. New York: NorthHolland, 2003. 